\title{
ČENĚK PACLT: EL TROTAMUNDOS CHECO EN MÉXICO Y BRASIL ${ }^{1}$
}

\author{
por JAROSLAV KŘÍŽ \\ (Universidad Carolina, Praga)
}

\section{Čeněk Paclt: Czech traveler in Mexico and Brazil}

\begin{abstract}
This article deals with American travels (mainly to stay in Mexico and Brazil) of Czech traveler Čeněk Paclt (1813-1887). Paclt belongs to the half-forgotten travelers of the nineteenth century, although in professional circles, his name is known. Among Czech adventurers and travelers, however, he has an important position, because he holds one primacy. Paclt is also the first Czech, who has provably traveled through all five inhabited continents and has left written evidence about his journeys. He came to the American land in the year 1846. Paclt traveled over Mexico, Brazil and large part of the East Coast of the United States of America. He went through Mexican territory during the Mexican-American War (1846-1848) as an American soldier. He was on the American continent in the years 1846-1857.
\end{abstract}

Keywords: Čeněk Paclt; traveler; Mexican-American War; 19th century

\section{Introducción}

El trotamundos checo Čeněk Paclt (1813-1887) nació hace 200 años en Turnov, es conocido como uno de los viajeros notables del siglo XIX. Entre los aventureros checos tiene un lugar destacado por haber alcanzado una primacía: Paclt viajó por los cinco continentes dejando testimonios escritos. Este artículo se enfoca en los viajes hechos por Paclt por México y Brasil, aproximadamente en la mitad del siglo XIX.

Durante su juventud Paclt aprendió a fabricar jabones, para obtener experiencia en su profesión recorría muchas ciudades de Europa central tratando de mantenerse fabricando jabones pero no prosperó en sus actividades. Al comienzo de los años 40 del siglo XIX estuvo afilando ópalos en una joyería de Viena y también negociaba con piedras preciosas en Varsovia pero su negocio no prosperaba. ${ }^{2}$ En menos de dos años gastó casi todos sus ahorros conseguidos en Viena y fue entonces que decidió

1 Este artículo es la versión modificada de algunas partes de la tesina - Jaroslav KŘíŽ, Cestovatel Čeněk Paclt (1813-1887) - první Čech na pěti kontinentech z pohledu historické antropologie [El trotamundos Čeněk Paclt (1813-1887) - el primer checo en los cinco continentes desde la perspectiva de la antropología histórica], Tesis de maestría, Praha 2013,93 páginas de manuscrito.

2 Čeněk PACLT, Jak jsem hledal zlato a diamanty [Como estaba buscando oro y diamantes], Praha 1947, pp. 7-8. 
abandonar Europa buscando suerte en el Nuevo Mundo sobre el cual había escuchado muchos rumores, ${ }^{3}$ en aquel momento tenía 33 años.

\section{Navegación al continente americano}

En septiembre del año 1846 Paclt subió a bordo de la embarcación "Thomas Bennet" dirigiéndose de Amberes a Nueva York, los viajeros eran generalmente alemanes e irlandeses. El trotamundos era el único checo ${ }^{4}$ en el barco, hecho que no sorprende puesto que la emigración checa a Estados Unidos llega a su máximo después del año 1848. Según registros oficiales en el período 1850-1900, partieron de Bohemia y Moravia más de 210000 personas. $^{5}$

El viaje a través del océano tardaba 31 días, la navegación era muy tormentosa, por eso los viajeros no podían quedarse en la superficie de la embarcación. La bodega carecía de aire respirable, había demasiado calor y en cada paso se oía el lamento de mujeres y niños, así como los sollozos de los enfermos. Čeněk Paclt sobreviviría al viaje con buena salud y el día 30 avistó Nueva York. La ciudad le daba mucha impresión, pero su entusiasmo no le duró mucho porque cada inmigrante tenía que ser muy cuidadoso frente a muchas bandas de ladrones (generalmente formadas por alemanes e irlandeses, ya que ellos siempre saludaban como "paisanos europeos" acompañándolos por la ciudad y en el momento menos esperado en algún lugar conveniente los atacaban y robaban, incluso algunas veces los asesinaban.) ${ }^{6}$ También Paclt había sido víctima de un robo; tal vez este hecho aceleró su partida de Nueva York hacia Nueva Orleans.

Čeněk Paclt se dirigía a trabajar en Luisiana pero desgraciadamente cerca de las Bahamas, el buque de vapor de nombre "Phoenix" en el que iba a bordo estalló y se incendió. Los pasajeros fueron salvados por la oportuna intervención de pescadores locales, incluso una gran parte de la carga fue trasladada del buque ardiente; también la nave de guerra "Providentia" colaboró en el rescate. Finalmente a salvo, Paclt estuvo contemplando los últimos segundos del buque de vapor "Phoenix" antes de que lo cubrieran las olas.

A bordo del buque militar se reunió con tres alemanes que en aquel tiempo servían en el ejército de los Estados Unidos, ellos le aconsejaron a Paclt para que entrara en el ejército como voluntario. Paclt no tardó mucho en decidir porque no tenía otros compromisos y escuchó sus consejos. En medio de una consulta realizada por el médico del barco, el aventurero de Turnov tomó brevemente la siguiente nota: "El médico me miró y escribió un mensaje diciendo está 'all right'."7 Después Paclt tomó juramento al capitán firmando un contrato por cinco años. En menos de

3 Jaroslav SVOBODA, Čeňka Paclta cesty po světě - Př́hody a zkušenosti jeho na cestách po Americe, Austrálii, Novém Zealandě a jižní Africe, Mladá Boleslav 1888, p. 372.

4 Ibidem p. 9.

5 Leoš ŠATAVA, Migrační procesy a české vystěhovalectví 19. století do USA [Procesos de migración y emigración checa del siglo XIX a los Estados Unidos], Praha 1989, p. 81.

6 Josef OPATRNÝ, Objevitelé, dobyvatelé, osadníci - 500 let Ameriky [Descubridores, conquistadores, colonos - 500 años de América], Praha 1992, p. 150.

7 Ibidem p. 150. 
una hora de realizado el rescate del buque de vapor, el viajero checo se convirtió en artillero de ejército de los Estados Unidos.

\section{En el territorio mexicano}

En esa época Estados Unidos estaba en guerra con México combatiendo sobre el territorio de Texas. La causa de este evento se puede rastrear ya desde los años veinte, cuando un gran número de estadounidenses (anglosajones) poblaron partes de Texas. ${ }^{8}$ El propio gobierno de México invitó a los inmigrantes a Texas porque necesitaba estabilizar la situación en las zonas fronterizas, donde acontecían conflictos entre colonizadores e indios. En los años siguientes muchos inmigrantes siguieron llegando, a mediados de los años treinta vivieron en el territorio de Texas casi diez veces más estadounidenses que mexicanos. Los eventos se llevaron a cabo de tal manera que el 2 de marzo los texanos anunciaron la independencia de Texas. Aunque los texanos vencieron a los mexicanos en la batalla de El Álamo, luego el 22 de abril fueron derrotados en la Batalla de San Jacinto. Entre los prisioneros estaba también el general Santa Anna, quien para salvar su vida firmó un tratado que reconocía la independencia de Texas. ${ }^{9}$ El gobierno de México nunca ratificó este tratado haciendo reclamaciones sobre el territorio perdido.

En 1845 la República de Texas aceptó la propuesta del Congreso sobre la unificación con los Estados Unidos, Texas se convirtió en el Estado 28 de la Unión. La guerra entre Estados Unidos y México tuvo lugar en 1846-1848 y se produjo por varias razones. Entre las principales se encuentra la anexión de Texas, los esfuerzos de la expansión territorial de los Estados Unidos hacia el suroeste y la inestabilidad política en México. "México estaba en una encrucijada: en bancarrota, sin aliados, carente de un ejército profesional, de armas, de municiones y de recursos económicos, y como si fuera poco, dividido entre monarquistas y federalistas, moderados y radicales." ${ }^{10}$ México no tuvo muchas ventajas ante Estados Unidos, pero el no apartar al agresor del norte era una cuestión de honor nacional.

En aquel tiempo Čeněk Paclt ya estaba en el servicio del Ejército de los Estados Unidos y llegó a Tampico - el puerto mexicano. De allí partieron refuerzos diarios a Veracruz, allá en la primavera de 1847 el general Winfield Scott concentraba sus fuerzas para tomar la ofensiva atacando el interior del país. Empujaban cada vez más las tropas del presidente mexicano Santa Anna que retrocedían aún más al interior de México. A veces ocurrían choques menores; pero las tropas estadounidenses sufrían menos pérdidas en comparación con los repentinos asaltos de las guerrillas. ${ }^{11}$ El General Scott lideraba su ejército de una manera similar como hace tres siglos lo hacía el conquistador Hernán Cortés, quien buscaba la capital del imperio azteca Tenochtitlán. ${ }^{12}$

8 Josefina Zoraida VÁZQUEZ, La intervención norteamericana 1846-1848, Ciudad de México 1997, p. 35 .

9 Ibidem pp. 48-49.

10 Ibidem p. 67.

11 OPATRNÝ, Objevitelé, p. 150.

12 Josefina Zoraida VÁZQUEZ, "México y la guerra con Estados Unidos", in: idem (ed.), México al tiempo de su guerra con Estados Unidos (1846-1848), Ciudad de México 1997, p. 37. 
El viajero checo llegó a Veracruz. Cerca de la ciudad había un campamento militar, que llevaba el nombre de "Camp Washington". Allí Paclt no se quedó mucho tiempo y pronto se fue con el ejército de los Estados Unidos hacia el interior para luchar contra las tropas mexicanas de Santa Anna. Los mexicanos defendieron el paso importante de Cerro Gordo, que dirigía hacia la capital de México. La Batalla de Cerro Gordo ocurrió el 18 de abril de 1847 y duró poco más de tres horas. El ejército americano ganaba con claridad y por eso se le abrió el camino hacia el interior de México. ${ }^{13}$ Los estadounidenses liderados por el general Scott luego prosiguieron a través de la ciudad de Puebla y San Martín.

En la localidad de San Martín, habiendo buscado agua con un soldado alemán, a Paclt le ocurrió un incidente curioso. Marchando por un paisaje desconocido fueron emboscados por los guerrilleros mexicanos. Paclt describió la situación de la siguiente manera:

En aquel momento sonó el ruido de caballos, y antes de que nos recuperáremos, se apresura a nosotros todo el grupo de corredores que nos rodearon inmediatamente, apuntando a nosotros sus rifles. Dos jinetes saltando ágilmente de sus caballos, nos lanzan un lazo alrededor del cuello, que cada jinete mexicano llevaba con él, y nos llevan con muchas amenazas al frente del oficial. Éste en primer lugar manda a los jinetes para que nos quiten todas las cosas de los bolsillos. En aquel entonces tenía sólo dos chelines, un adjunto de acompañamiento y en ella un escrito doblado, indicando a mi hermano, en aquel tiempo un sacerdote de Tejn de Rovensko con el domicilio inglés: 'Sacerdote, Bohemia'. Mi compañero Ball no tenía dinero, sólo una pipa con un retrato de Rongo, un famoso sacerdote de Silesia prusiana. ${ }^{14}$

El líder de la guerrilla nos interrogaba a ambos. Cuando se dio cuenta de que ni el uno ni el otro procedíamos de América y de que éramos católicos, en vez de colgarnos el día siguiente nos despidió. Esta breve historia es testimonio de que incluso en la guerra hay reglas. También muestra la caballerosidad del líder del grupo de soldados mexicanos que no sucumbía a la ferocidad de la guerra, y al contrario, gracias a su percepción religiosa había salvado dos vidas.

El ejército de Estados Unidos siguió marchando hacia la ciudad de México. ${ }^{15}$ A Paclt le encantaba el paisaje espectacular que los estaba rodeando, y lo describió de la siguiente manera:

Un valle vasto se extendía ante nosotros en un verdor abundante, con palmeras hermosas y pájaros de los más vistosos colores. En el lado izquierdo se alzaba el monte Popocatépetl cubierto en el medio por nieve eterna y calva hasta la corona. En la distancia brillaba la superficie del lago Chalk [Chalco] y detrás de él, en el lado derecho de la carretera, se extendía el segundo lago Tezkuko [Texcoco], en el cual ya

13 Karl Jack BAUER, The Mexican War: 1846-1848, Lincoln 1992, pp. 265-268.

14 Čeněk PACLT, Cesty světem - Příhody a zkušenosti na cestách po Americe, Austrálii, Novém Zélandě a jižní Africe [Viajes por el mundo: eventos y experiencias en la carretera en América, Australia, Nueva Zelanda y Sudáfrica], Praha 1954, p. 27.

15 Josef KUNSKÝ, Čeští cestovatelé I [Viajeros Checos I], Praha 1961, p. 366. 
se reflejaban las sombras de la ciudad en aquel momento tapada por la niebla. Era la sede de Moctezuma famosos [Aztecas] y por ahora el objetivo de nuestros deseos fervientes. ${ }^{16}$

El 19 de agosto de 1847 los estadounidenses conquistaron la fortaleza Contreras y por lo tanto tenían un camino libre hasta la ciudad de México. Alrededor de la capital habían varias fortalezas que los estadounidenses también expugnaron. En una batalla Paclt sufrió una herida de bala, afortunadamente era sólo una herida leve por lo cual se curó muy pronto. Hasta el final de su vida le quedó en la mano una cicatriz que le recordaba esa experiencia bélica.

El Ejército de Scott superó los muros de la ciudad capital durante la noche del 13 de septiembre al 14 septiembre de 1847. A la ciudad entró también Čeněk Paclt, que más tarde recordaría:

Los soldados y habitantes mexicanos dispersados por todos los edificios, nos disparaban de todos lados, de ventanas y azoteas de manera que no era posible adentrarse a ninguna calle y apoderársela. A pesar de ello, algunos de nuestros soldados lograron romper las paredes de algunas casas en la planta baja y de esta manera penetraron. Luego, en una casona muy alta había sido arrancado un obús del cual se disparaban a esas casas. Cada casa desde la cual sonaba un tiro, estaba condenada al saqueo. ${ }^{17}$

El centro de la ciudad era descrito por Paclt con estas palabras:

La plaza mexicana es un gran cuadrangular pavimentado. Uno de los lados, donde en otro tiempo estaba situado un palacio de Moctezuma, ocupaba la casa de gobierno, de la segunda parte se alzaba un templo magnífico con una torre dorada hasta la parte superior, con el cual confinaba un palacio arzobispal. La misma ciudad ostenta edificios hermosos, tenía su propia universidad, cientos de templos y cincuenta monasterios (anteriormente era alrededor de un centenar), entre muchos otros institutos benéficos. La ciudad es un centro de comercio, gracias a su ubicación en el medio del camino entre dos puertos de Veracruz y Acapulco. Todavía hay muchos vestigios de educación de los primeros habitantes aztecas, especialmente las ruinas de templos y otras estructuras enormes con arabescos y jeroglíficos. Incluso las carreteras que conectan la ciudad hasta ahora con otros asentamientos son todavía restos de paganos y dan el más elocuente testimonio de tan nivel alto de erudición al cual los aztecas lograron.”18

Más tarde en la primavera de 1848 Paclt participó en las expediciones militares exitosas en Orizaba y Córdoba. El tratado de paz había sido suscrito el 2 de 1848 en Guadalupe Hidalgo, pero el ejército estadounidense abandonó la capital de México el 12 de junio de 1848. ${ }^{19}$ Después de la guerra Estados Unidos - México, Paclt volvió con el ejército a Estados Unidos, a Nueva York.

16 SVOBODA, Čeňka Paclta, p. 20.

17 OPATRNÝ, Objevitelé, p. 150.

18 PACLT, Cesty, pp. 33-34.

19 Josef OPATRNÝ, Stát osamělé hvězdy a mexicko-americká válka [El estado de la estrella solitaria y la guerra mexicano-americana], Praha 2002, p. 350. 
Čeněk Paclt conoció el conflicto mexicano-estadounidense a través de su participación por una parte considerable del territorio mexicano. Además de las batallas militares en las que vivió muchas aventuras peligrosas, también pudo admirar el paisaje notable y lugares históricos, que describe en su libro de viajes. La profesión de soldado le permitió una vista inusual de la cultura mexicana y por supuesto de la cultura americana. Después de dos años en América ya tenía muchas experiencias, pero su deseo de hacer viajes no estaba satisfecho, por lo que permaneció en el territorio de los Estados Unidos. Los siguientes tres años los sirvió en el ejército y en la fortificación de St. Agustine en la Florida y luego en Charleston en el Estado de Carolina del Sur. Por haber servido cinco años obtuvo varios cientos de dólares y un abono para 160 acres de tierra federal gratuita. Por el servicio militar también recibió la ciudadanía de Estados Unidos.

\section{El viaje brasileño}

En la primera mitad de los años cincuenta Paclt estuvo viajando por una gran parte de la costa este de los Estados Unidos. En 1856 enfermó de escalofríos, no podía curarse, intentó todo lo posible, pero sin éxito. Siguiendo el consejo de un médico decidió trasladarse. Brasil llegó a ser su nuevo destino por los yacimientos de diamantes, zafiros y rubíes. El largo viaje desde Savannah a Río de Janeiro no produjo a Paclt la curación deseada, la llegada al puerto fue descrito por Paclt de esta manera:

Llegamos felizmente a la encantadora bahía de la ciudad capital de Brasil. Si uno mira Río de Janeiro con las naves, tiene por delante una visión de la belleza impresionante. La ciudad está situada pintorescamente junto a la superficie del agua y la sierra de formas extrañas formando un magnífico telón de fondo. Subiendo la superficie, miré hacia adelante para aprender sobre la búsqueda de piedras preciosas. Todos me aseguraban que nadie podía conseguirlo, puesto que el intento sería desatinado e inútil. ${ }^{20}$

Por lo tanto, un decepcionado Paclt buscó el primer barco hacia el norte y regresó a Nueva York. Río de Janeiro no le hizo a Čeněk Paclt una buena impresión, a excepción de una impresionante vista de la bahía. Según Paclt las calles eran irregulares y muy sucias, no le gustaron tampoco los edificios.

Y la misma residencia imperial es una vivienda bastante miserable. Por todas partes hay un movimiento extraordinario. Gente blanca, negra y marrón corre por calles en repentina prisa. Negros arrastrando carga, vendedores gritando, cuadrilla de barqueros jadeando, grupos de soldados a pie o a caballo, peatones holgazaneando, todo en una mezcla no elegante, de manera que a un observador le ocurre en cada momento una escena nueva. ${ }^{21}$

Paclt regresó a Nueva York, visitó un médico famoso francés, porque aún le afligían los escalofríos. Incluso éste no le sirvió de nada y sólo le recomendaba que

20 SVOBODA, Čeňka Paclta, p. 47.

21 PACLT, Cesty, p. 49. 
se fuera del continente. Paclt decidió viajar a Australia. Por 100 dólares compró un billete de segunda clase en el buque de vapor "Marie Banks" y el 1 de mayo 1857 navegó hacia el mar abierto. Durante la navegación Paclt se curó. Nunca regresó al continente americano. Sobre América sólo podía leer en los periódicos. Tras los años de haber vivido allí, conoció una gran parte del país y ganó muchas experiencias que utilizó en otros viajes por todo el mundo.

\section{Conclusión}

El aventurero de Turnov es uno de los más conocidos viajeros checos del siglo XIX al lado de E. Holub, E. S. Vráz, A. V. Frič y muchos otros. Se trata de una persona destacada en cuanto a viajes, no sólo por el hecho de que supuestamente visitó como primer checo los cinco continentes ${ }^{22}$ sino también por sus aventuras. Čeněk Paclt consiguió reconocimiento entre sus vecinos de Turnov: una calle ha sido nombrada por él. A memoria de Paclt hay muchos artefactos depositados en Muzeum Českého ráje (Museo del paraíso checo).

Hay que destacar que a diferencia de Emil Holub, Paclt no es un ejemplo de "viajero - profesional". A diferencia de Holub, ${ }^{23}$ los viajes de Paclt no fueron financiados por ninguna institución, patrón, ni tampoco por el Estado. Así pues durante sus viajes por el mundo Paclt ejercía oficios diversos, mencionando algunos: soldado, granjero, cocinero o comerciante. No era caprichoso, utilizaba todas las posibilidades para ganarse la vida. Debido a este enfoque el conoció la vida pública en Estados Unidos, Australia, Nueva Zelanda y Sudáfrica. Cuando no estaba en su patria, la recordaba con amor. En sus pensamientos soñaba con volver a Bohemia y a menudo comparaba el paisaje checo con la naturaleza diferente tal como la reconocía en el extranjero. También era un gran patriota y le gustaba discutir cuestiones políticas, por lo que también tomó afición en la sociedad americana a la cual la medida de la censura no era tan alta, como en Países Checos en aquel tiempo.

Después de haber viajado por los Estados Unidos, México y Brasil, Paclt visitó una parte considerable de Australia y Nueva Zelanda. Poco tiempo pasó en Asia, específicamente en India. Este continente no le impresionó mucho. En la segunda mitad de los años sesenta del siglo XIX estuvo viviendo en Bohemia. Por razones políticas, tuvo que huir de Bohemia y decidió viajar por el continente africano. Lo atraían los rumores de hallazgos de diamantes en la Provincia del Cabo, en Sudáfrica. En enero de 1870 embarcó para navegar de Southampton al "continente negro". En África, estuvo casi diecisiete años. Paclt ya nunca volvió a su tierra natal, murió en junio de 1887 en una tienda de campaña en Keiskama junto al río Vaal.

A pesar de los estímulos de sus amigos, Paclt nunca quiso escribir sus viajes en una obra íntegra. Los relatos de viaje de su época se le parecían más bien a literatura fantástica, la cual deformaba la realidad. Sin embargo, sus amigos consiguieron convencerlo para que escribiera sus experiencias. En 1888, un año después de la

\footnotetext{
22 Michael BOROVIČKA, Velké dějiny zemí Koruny české - Cestovatelství [Gran historia de las tierras checas - Viajes], Praha/Litomyšl 2010, p. 186.

23 Ibidem, pp. 421-423.
} 
muerte de Paclt, un amigo del viajero -Jaroslav Svodoba- recolectó sus cartas y apuntes, y llegó a publicarlas en una edición completa.

(Traducido al español por Pavel Šmída)

\section{BIBLIOGRAFÍA}

BAUER, Karl Jack, The Mexican War: 1846-1848, Lincoln: University of Nebraska Press, 1992.

BOROVIČKA, Michael, Velké dějiny zemí Koruny české - Cestovatelství, Praha/Litomyšl: Paseka, 2010.

KŘÍŽ, Jaroslav, Cestovatel Čeněk Paclt (1813-1887) - první Čech na pěti kontinentech z pohledu historické antropologie, Tesis de maestría, Praha: Univerzita Karlova v Praze 2013, 93 páginas de manuscrito.

KUNSKÝ, Josef, Čeští cestovatelé I, Praha: Orbis, 1961.

OPATRNÝ, Josef, Objevitelé, dobyvatelé, osadníci - 500 let Ameriky, Praha: ROAD, 1992.

OPATRNÝ, Josef, Stát osamělé hvězdy a mexicko-americká válka, Praha: Libri, 2002.

PACLT, Čeněk, Cesty světem - Příhody a zkušenosti na cestách po Americe, Austrálii, Novém Zélandě a jižní Africe, Praha: Orbis, 1954.

PACLT, Čeněk, Jak jsem hledal zlato a diamanty, Praha: Melantrich, 1947.

SVOBODA, Jaroslav, Čeňka Paclta cesty po světě - Příhody a zkušenosti jeho na cestách po Americe, Austrálii, Novém Zealandě a jižní Africe, Mladá Boleslav: Karel Vačlena, 1888.

ŠATAVA, Leoš, Migrační procesy a české vystěhovalectví 19. století do USA, Praha: Univerzita Karlova, $1989,81$.

VÁZQUEZ, Josefina Zoraida, México y la guerra con Estados Unidos, in: J. Z. Vázquez (ed.), México al tiempo de su guerra con Estados Unidos (1846-1848), Ciudad de México: Secretaría de Relaciones Exteriores, 1997.

VÁZQUEZ, Josefina Zoraida, La intervención norteamericana 1846-1848, Ciudad de México: Secretaría de Relaciones Exteriores, 1997.

\section{Breve información sobre el autor}

Doctor en el Departamento de Etnología de la Facultad de Filosofía de la Universidad Carolina. Se centra en la historia de los viajes y los problemas de migración (especialmente los checos en los Estados Unidos). Prepara un libro sobre el viajero Čeněk Paclt (edición 2019 o 2020). 